\title{
Fermentation of wheat bran and gum arabic in rats fed on an elemental diet
}

\author{
By D. J. WALTER*, M. A. EASTWOOD† and W. G. BRYDON \\ Wolfson Laboratories, Gastrointestinal Unit, Department of Medicine, \\ University of Edinburgh, Western General Hospital, Edinburgh EH4 $2 X U$ \\ AND R. A. ELTON \\ Medical Statistics Unit, Faculty of Medicine, University of Edinburgh, Teviot Place, \\ Edinburgh EH8 9AG
}

(Received 7 April 1988-Accepted 4 May 1988)

1. Gum arabic and wheat bran were added to an elemental diet $(100 \mathrm{~g} / \mathrm{kg})$ in order to study their metabolism in the caeca of adult male albino Wistar rats.

2. Dry stool weight ( $\mathrm{g} / \mathrm{d}$ ) over 12 weeks was 0.70 (SE 0.05 ) on the elemental control diet. Wheat bran increased mean dry stool weight to 1.09 (SE 0.08), an increase of $56 \%$. There was no significant difference between faecal weights (0.65 (SE 0.08)) of the gum-arabic-supplemented group and the unsupplemented group.

3. Wet caecal-sac weight, dry caecal-contents weight, and faecal and caecal bacterial mass (measured by 2,6diaminopimelic acid) all increased significantly with the gum-arabic-supplemented diet but not with the wheatbran-supplemented diet.

4. Total short-chain fatty acids (mostly acetate) increased in the caecum and faeces with the gum-arabicsupplemented diet but not with the wheat-bran-supplemented diet.

5 . Breath hydrogen and methane production decreased to negligible amounts over the 12 weeks of the experiment.

In man, dietary fibre passes through the upper gastrointestinal tract and small intestine to the caecum. It is generally believed that there is no metabolism of fibre before reaching the caecum. In the caecum, fibre is fermented to a variable extent, depending on the nature of the fibre. Such fermentation can lead to changes in the caecal size, bacterial mass, and the production of carbon dioxide, methane, hydrogen and short-chain fatty acids (SCFA) (Winitz et al. 1970; Rodkey et al. 1972; Leegwater et al. 1974; Cummings et al. 1978). Faecal weight and constituents are also affected by the fibre content of the diet (Williams \& Olmsted, 1936 $a, b$; Eastwood \& Mitchell, 1976). In addition to the fibre content of the diet, it would appear that the overall diet in which the fibre is included may affect the metabolism of fibre by the caecal microflora, and the faecal output (Wise et al. 1986).

The present experiment was designed to investigate the influence of the duration of feeding of two fibre supplements, coarse wheat bran and gum arabic (a readily fermentable complex polysaccharide) on certain indices of fibre metabolism, when given in addition to an elemental, low-residue, nutritionally complete diet. Subsequent effects on the metabolism of the dietary supplements in the caecum, colon and faeces were recorded.

\section{MATERIALS AND METHODS}

Forty-five male albino adult rats, approximately 3 months old, supplied by the Animal Unit, Western General Hospital, Edinburgh, of inbred Wistar strain from the Unit, live

* Present address: Central Analytical Laboratory/Trace Element Department, Edinburgh School of Agriculture, Kings Buildings, West Mains Road, Edinburgh EH9 $3 \mathrm{JG}$.

+ For reprints. 
weight 382 (SE 5.6) g, were caged in nine groups of five on shavings and sawdust and kept at $21-21 \cdot 5^{\circ}$ with a $12 \mathrm{~h}$ light $-12 \mathrm{~h}$ dark cycle. Water was freely available. These animals had been fed since weaning on a small-animal diet (Labsure) before changing to the elemental diet, with or without supplementation, at the beginning of the experiment.

A low residue, nutritionally complete elemental diet (Flexical; Mead Johnson, Langley, Slough) was used. This is an elemental diet containing amino acids and simple sugars. It contained $(/ \mathrm{kg}) 99 \mathrm{~g}$ protein, $669 \mathrm{~g}$ carbohydrate and $150 \mathrm{~g}$ fat supplying $17850 \mathrm{~kJ}$ and was made up of glucose syrup solids, protein hydrolysate powder, soya-bean oil, modified tapioca starch, medium-chain triglycerides, calcium citrate, potassium chloride, dibasic magnesium phosphate, lecithin, potassium citrate, methionine, choline chloride, calcium phosphate, tyrosine, sodium ascorbate, tryptophan, nicotinamide, ferrous sulphate, zinc sulphate, DL- $\alpha$-tocopheryl acetate, calcium pantothenate, manganese sulphate, copper sulphate, vitamin $\mathbf{B}_{1}$, vitamin $\mathbf{B}_{6}$, vitamin $\mathbf{B}_{2}$, vitamin $A$, folic acid, biotin, vitamin $\mathbf{K}_{1}$, potassium iodide, vitamin $B_{12}$ and vitamin $D$.

The coarse Canadian Red spring wheat bran (Chancelot Mills, Edinburgh) contained ( $\mathrm{g} / \mathrm{kg}$; Southgate method of analysis) $175 \mathrm{starch}, 4.4$ pectin, 228 hemicellulose, 97 cellulose and 4.7 lignin, and $54 \%$ passed through a $1.5 \mathrm{~mm}$ seive.

Elemental $(E)$ diet. $150 \mathrm{~g}$ Flexical powder, $12 \mathrm{~g}$ gelatin (AnalaR; BDH) and $240 \mathrm{ml}$ warm water were mixed together and allowed to set.

$E$ and $100 \mathrm{~g}$ gum arabic/ $\mathrm{kg}(E G)$ diet. $134 \mathrm{~g}$ Flexical powder, $17 \mathrm{~g}$ gelatin, $17 \mathrm{~g}$ gum arabic and $250 \mathrm{ml}$ warm water were mixed together and allowed to set.

$E$ and $100 \mathrm{~g}$ coarse bran $/ \mathrm{kg}(E B)$ diet. $133.8 \mathrm{~g}$ Flexical powder, $12 \mathrm{~g}$ gelatin, $16.2 \mathrm{~g}$ coarse bran (supplied by Chancelot Mills, Edinburgh) plus $240 \mathrm{ml}$ warm water, were mixed together and allowed to set.

Each mix was sufficient to feed five rats/d. The forty-five rats on these regimens were divided into three groups of fifteen and fed on diet E, EG or EB. Food residues were weighed daily and estimates of food intake made. Rats on diet $\mathrm{E}$ ate approximately $28 \mathrm{~g} / \mathrm{d}$, on diet EG $25 \mathrm{~g} / \mathrm{d}$ and on diet EB $26 \mathrm{~g} / \mathrm{d}$. All rats were weighed every $7 \mathrm{~d}$ at the same time each week. All teeth were clipped every 2 weeks to prevent excessive elongation (Walter, 1985).

Three groups of fifteen rats, each eating diet E, EG or EB, were subdivided so that within each group of fifteen rats, five were fed for 4 weeks, five were fed for 8 weeks and the remaining five were fed for a total of 12 weeks. This was the procedure for each diet. Before killing, the rats were placed in individual broad-spaced, gridded cages to facilitate a $3 \mathrm{~d}$ stool collection for wet faecal weights. The stools were collected at frequent intervals over the $3 \mathrm{~d}$ period. The faecal mass was adjusted to $\mathrm{pH} 8.0$ before being frozen, freeze-dried and reweighed (dry weight).

Five rats were thus killed every 4 weeks, in the morning, by diethyl ether anaesthesia. The caecal contents were removed, weighed, adjusted to $\mathrm{pH} 8$ and stored separately. $\mathrm{H}_{2}$ and $\mathrm{CH}_{4}$ production were estimated by placing a rat of known weight in an air-tight Perspex box (12 litre volume) for $15 \mathrm{~min}$. After this time a $50 \mathrm{ml}$ sample of head-space gas was removed and analysed by gas-solid chromatography (Tadesse et al. 1979) using a Pye 104 chromatograph.

The collection of gas for $\mathrm{CH}_{4}$ and $\mathrm{H}_{2}$ analyses over 15 min was compared at different times of day from the same rat. The coefficient of variation for the repeat analysis of a standard $20 \mathrm{ppm}$ sample $(n 77)$ was $11 \%$ for $\mathrm{H}_{2}$ and $14 \%$ for $\mathrm{CH}_{4}$ (Walter, 1985). The quantitative collection and determination of $\mathrm{H}_{2}$ gas from the rat was affected by the time of day. In these experiments the measurements were always made at the same time of day, in the morning (McKay, 1981). 
The following measurements were made: SCFA (Spiller et al. 1980) and 2,6diaminopimelic acid (DAPA) (Czerkawski, 1974).

All results quoted are means with their standard errors. Results were compared using a two-factor analysis of variance with replication.

\section{RESULTS}

All animals gained weight over the 12-week feeding period and this was significantly related to duration of feeding $(P<0.01)$. The rats weighed between 337 (SE 12) and 409 (SE 17) $\mathrm{g}$ in their initial groups. Over 12 weeks the rats fed on diet EG gained significantly less weight (mean 92 (SE 8) g) than the rats fed on diets E and EB (123 (SE 11) and 114 (SE 9) $\mathrm{g}$ respectively); between diets $\mathrm{E}$ and $\mathrm{EB}$ there was no significant difference. Overall mean liveweight gain (g) at 4 weeks was 71 (SE 5), at 8 weeks 10 (SE 4) and at 12 weeks 148 (SE 7).

Table 1 summarizes the statistical significance of the effects of diet, time of feeding and the interaction of diet and time for all indices measured.

Table 2 shows values for measurements made during the feeding trial. Dry stool weight increased with time $(P<0.05)$, there being an overall significant difference between $4(0.68$ (SE 0.08) g) and 12 weeks (0.91 (SE 0.33) g) and was higher with diet EB than with the other diets $(P<0.01)$ at all time-intervals. Diet significantly influenced caecal-sac wet weight $(\mathrm{CSWW})(P<0.01)$. CSWW was greatest with diet EG at all time-intervals and lowest with diet $E$. There was a significant interaction between diet and duration of feeding for CSWW : with diets EG and E, CSWW decreased after 4 weeks whilst with diet EB, CSWW increased $(P<0.01)$. Only within the EG diets was there no significant difference between 4,8 and 12 weeks. Dry caecal content increased with all diets $(P<0.01)$ but was highest with diet EG at all time-intervals. There was no overall significant difference between diets EB $(0.54$ (SE 0.03) g) and E (0.46 (SE 0.04) g). On all three regimens, the dry caecal content had apparently stabilized by 4 weeks, as there was no significant effect of time with any of the diets, nor was there any significant interaction between diet and time.

Total dry caecal and faecal DAPA was higher with diet EG than with the other two diets at all three time-periods $(P<0 \cdot 01)$. There was no overall significant difference between diets $E$ and $E B$ for either caecal or faecal material, nor was there any significant difference between time-intervals with any of the diets. With diet EG caecal DAPA was increased by approximately threefold and faecal DAPA by approximately twofold. The overall concentration of DAPA, both in the caecum and faeces, was greatest with diet EG and lowest with diet EB at all three time-intervals $(P<0.01)$. With caecal DAPA, the concentration decreased after 4 weeks on each diet $(P<0 \cdot 05)$, illustrating that the change with time in concentration was similar for each diet. With the concentration of faecal DAPA the interaction of diet and time was significant $(P<0.05)$, showing that whilst the concentration of DAPA was, overall, greatest on diet EG at all time-intervals and lowest with diet EB, the three diets did not behave the same with time (Table 2), i.e. the change in concentration over time varied with diet.

There was a steady decline in $\mathrm{H}_{2}$ and $\mathrm{CH}_{4}$ produced with all regimens. By 12 weeks virtually all $\mathrm{H}_{2}$ and $\mathrm{CH}_{4}$ production had ceased. Diet EG produced the most $\mathrm{H}_{2}$ and $\mathrm{CH}_{4}$ at all three time-intervals $(P<0.01)$. With time, $\mathrm{CH}_{4}$ levels did not alter significantly with any diet, but for $\mathrm{H}_{2}$ an interaction of diet and time $(P<0.01)$ was recorded, indicating that the change in concentration between time-intervals was different with each diet.

Total caecal SCFA were highest on diet EG $(P<0.01)$ at all three time-intervals compared with diets E (263 (SE 27) g) and EB (259 (SE 16) g) between which there was no significant difference. The duration of feeding was not significant. Total faecal SCFA were 
Table 1. A summary of the statistical assessment of the effects of feeding rats on an elemental diet alone or supplemented with $100 \mathrm{~g}$ gum arabic/ $\mathrm{kg}$ or $100 \mathrm{~g}$ wheat bran $/ \mathrm{kg}$ for three time periods $\dagger$

\begin{tabular}{|c|c|c|c|}
\hline Variable & Diet & Time & Interaction \\
\hline \multicolumn{4}{|l|}{ Live-wt (g) } \\
\hline Initial & $2 \cdot 11 \mathrm{NS}$ & $2 \cdot 73 \mathrm{NS}$ & $3.90^{*}$ \\
\hline Final & $4 \cdot 21^{* *}$ & $21 \cdot 5^{* *}$ & $3.26 \mathrm{NS}$ \\
\hline Live-wt change (g) & $15 \cdot 8^{* *}$ & $91 \cdot 4^{* *}$ & $1.21 \mathrm{NS}$ \\
\hline \multicolumn{4}{|l|}{ Stool dry wt } \\
\hline g & $12 \cdot 6 * *$ & $3 \cdot 48^{*}$ & $1.67 \mathrm{NS}$ \\
\hline $\mathrm{g} / \mathrm{kg}$ & $9 \cdot 88^{* *}$ & $1.72 \mathrm{NS}$ & $1.56 \mathrm{Ns}$ \\
\hline \multicolumn{4}{|l|}{ Caecum sac wet wt (empty) } \\
\hline g & $106^{* *}$ & $2.00 \mathrm{Ns}$ & $4 \cdot 50^{* *}$ \\
\hline $\mathrm{g} / \mathrm{kg}$ & $111^{* *}$ & $15 \cdot 6^{* *}$ & $3 \cdot 80^{*}$ \\
\hline \multicolumn{4}{|l|}{ Dry caecal contents } \\
\hline $\mathrm{g}$ & $78 \cdot 5^{* * *}$ & $2 \cdot 50 \mathrm{NS}$ & $2 \cdot 00 \mathrm{NS}$ \\
\hline $\mathrm{g} / \mathrm{kg}$ & $177^{* *}$ & $0.30 \mathrm{Ns}$ & $1 \cdot 20 \mathrm{NS}$ \\
\hline \multicolumn{4}{|l|}{ DAPA } \\
\hline \multicolumn{4}{|l|}{ Total } \\
\hline Caecal $(\mu \mathrm{mol})$ & $102^{* *}$ & $1.50 \mathrm{NS}$ & $0.97 \mathrm{NS}$ \\
\hline Faecal $(\mu \mathrm{mol} / \mathrm{d})$ & $11 \cdot 9^{* *}$ & $0.81 \mathrm{NS}$ & $1.05 \mathrm{NS}$ \\
\hline \multicolumn{4}{|l|}{ Concentration } \\
\hline Caecal $(\mu \mathrm{mol} / \mathrm{g})$ & $22 \cdot 8^{* *}$ & $3.64^{*}$ & $0.42 \mathrm{NS}$ \\
\hline Faecal $(\mu \mathrm{mol} / \mathrm{g})$ & $182^{* *}$ & $4 \cdot 85^{*}$ & $4 \cdot 11^{*}$ \\
\hline \multicolumn{4}{|l|}{ SCFA } \\
\hline \multicolumn{4}{|l|}{ Total } \\
\hline Caecal $(\mu \mathrm{mol})$ & $21 \cdot 3^{* *}$ & $2.23 \mathrm{NS}$ & $1.38 \mathrm{NS}$ \\
\hline Faecal $(\mu \mathrm{mol} / \mathrm{d})$ & $10 \cdot 5^{* *}$ & $4 \cdot 43^{*}$ & $2 \cdot 21 \mathrm{NS}$ \\
\hline \multicolumn{4}{|l|}{ Concentration } \\
\hline Caecal $(\mu \mathrm{mol} / \mathrm{g})$ & $2.92 \mathrm{NS}$ & $7 \cdot 23^{* *}$ & $2.44 \mathrm{NS}$ \\
\hline Faecal $(\mu \mathrm{mol} / \mathrm{g})$ & $23 \cdot 3^{* *}$ & $460^{*}$ & $3 \cdot 32^{*}$ \\
\hline \multicolumn{4}{|l|}{ Individual SCFA $(\mathrm{mmol} / \mathrm{mol})$} \\
\hline \multicolumn{4}{|l|}{ Caecal } \\
\hline Acetate & 4.43* & $\mathrm{I} \cdot 13 \mathrm{NS}$ & $3 \cdot 95^{*}$ \\
\hline Propionate & $28 \cdot 7^{* *}$ & $0.38 \mathrm{Ns}$ & $0.81 \mathrm{NS}$ \\
\hline Butyrate & $14 \cdot 5^{*}$ & $2.66 \mathrm{NS}$ & $2 \cdot 37 \mathrm{NS}$ \\
\hline \multicolumn{4}{|l|}{ Faecal } \\
\hline Acetate & $12 \cdot 7^{* *}$ & $8.91^{* *}$ & $3 \cdot 17^{*}$ \\
\hline Propionate & $1.31 \mathrm{NS}$ & $2 \cdot 14 \mathrm{NS}$ & $4 \cdot 62^{* *}$ \\
\hline Butyrate & $1 \cdot 80^{* *}$ & $8 \cdot 84^{* *}$ & $10 \cdot 1^{* *}$ \\
\hline Hydrogen $(\mathrm{ml} / \mathrm{h}$ per $\mathrm{kg})$ & $14 \cdot 5 * *$ & $20 \cdot 8^{* *}$ & $6 \cdot 60^{* *}$ \\
\hline Methane $(\mathrm{ml} / \mathrm{h}$ per kg) & $5 \cdot 40^{* *}$ & $2 \cdot 50 \mathrm{NS}$ & $2 \cdot 20^{* *}$ \\
\hline df & 2,36 & 2,36 & 4,36 \\
\hline \multicolumn{4}{|l|}{$\mathrm{df}$ for } \\
\hline total and individual SCFA (faecal) & 2,35 & 2,35 & 4,35 \\
\hline DAPA (faecal) & 2,35 & 2,35 & 4,35 \\
\hline
\end{tabular}

Ns, not significant; DAPA, 2,6-diaminopimelic acid; SCFA, short-chain fatty acids. $* P<0.05, * * P<0.01$.

$\dagger$ For details of diets, see p. 226.

increased $(P<0.01)$ with diets EG (116 (SE 15) g) and EB (134 (SE 16) g) compared with diet E $(57.5(\mathrm{SE} 11.5) \mathrm{g})$. Total faecal SCFA increased with time $(P<0.05)$ with each diet, the overall difference between 4 weeks and 8 and 12 weeks being significant.

With all diets, acetate was the major SCFA in both dried caecal contents and dried faeces. Caecal isobutyrate, isovalerate and valerate were present only in small amounts in both dried caecal and dried faecal matter. 
Fermentation of wheat bran and gum arabic

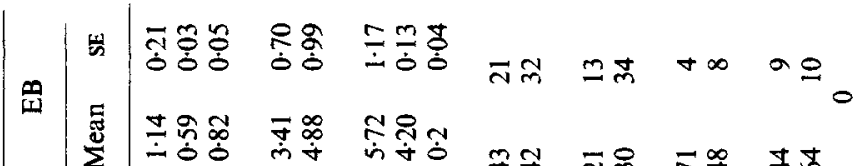

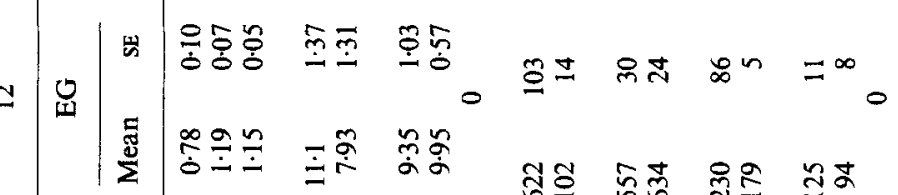

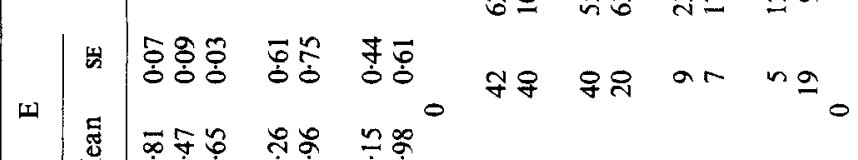

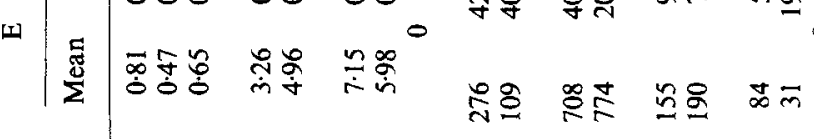

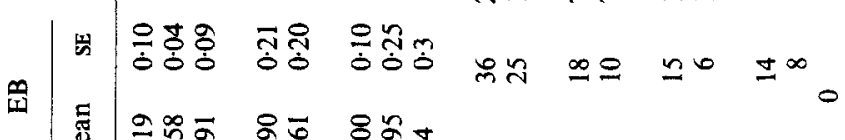

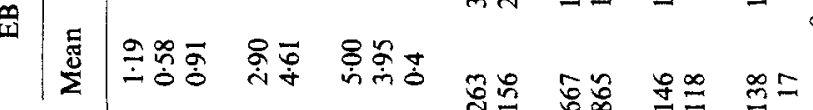

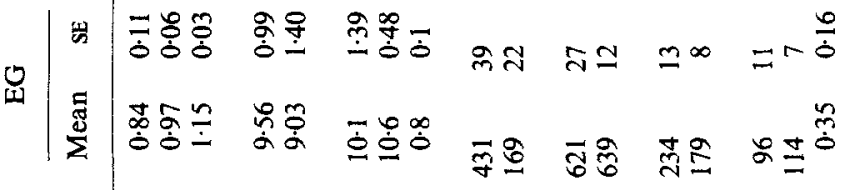

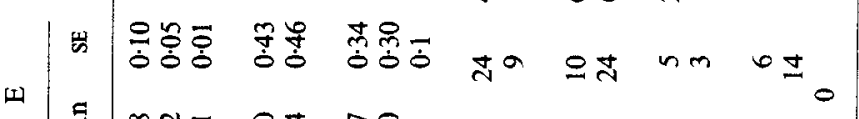
山| |⿹ 四|

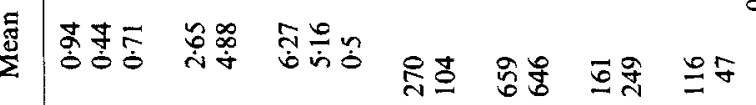
$\infty+\infty \sum$ :

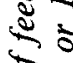

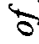

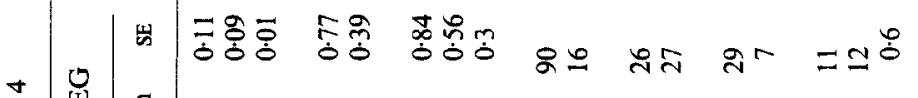
+|

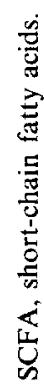
5

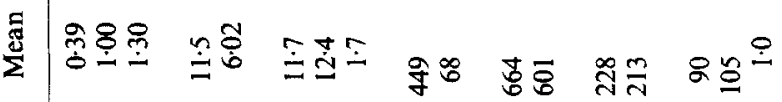

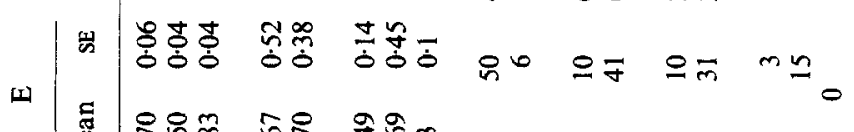

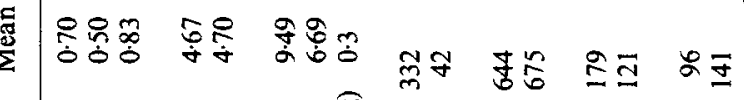

音

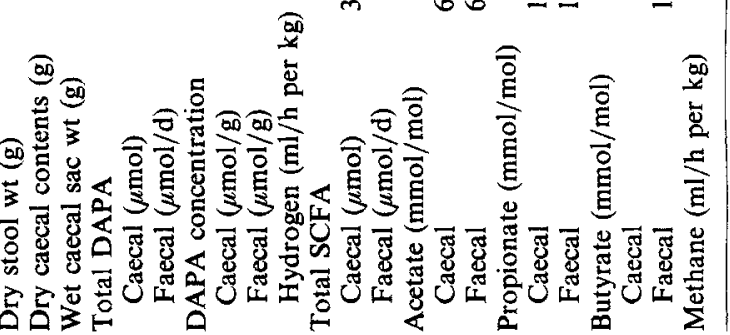


Whilst diet EG was associated with an overall decline in caecal acetate, the interaction of diet and time was significant $(P<0.01)$, highlighting the change in concentration over time with different diets. Whilst diet $\mathrm{E}$ (12 weeks) stimulated the highest proportion of caecal acetate, only the difference between diets EG (12 weeks) and E (12 weeks) was significant $(P<0.01)$, with no significant difference between diet EG (12 weeks), diet E (12 weeks) and the intermediate six groups. The overall proportion of faecal acetate was also significantly reduced with diet EG compared with diets $\mathrm{E}$ and $\mathrm{EB}(P<0.01)$ at all timeintervals. The proportion of faecal acetate did increase with time with all diets, there being a significant difference between 4 and 8 weeks, but the interaction of diet and time was significant $(P<0.05)$. The change between time-intervals was different for each diet, one diet given for one time-interval giving a similar result to that of another diet given for a different time-interval. In this case diet EB ( 8 weeks) gave significantly greater values than diet EB (4 and 12 weeks), but diet EG (12 weeks) was not significantly different from diet E (8 weeks).

Diet EG significantly increased caecal propionate $(P<0.01)$ at all time-intervals. There was no overall significant difference between diets E (165 (SE 5) g) and EB (160 (SE 6) g) and no significant effect of the duration of feeding. In contrast, only the interaction of diet and time was significant with faecal propionate $(P<0-01)$. Whilst with time the proportion of propionate decreased with diets EB and EG, the proportion increased with diet $\mathrm{E}$. After 12 weeks there was no significant difference between diets E, EG or EB, again emphasizing how different diets can behave in different ways over time, and produce a similar end result.

Caecal butyrate was highest with diet EB at all time-intervals compared with diets $\mathrm{E}$ and EG $(P<0.01)$ between which there was no significant difference. Duration of feeding was not significant for any of the three diets and there was no overall significant difference between diets $\mathrm{E}$ and EG. Diet, time and the interaction of diet and time were all significant $(P<0.01)$ for faecal butyrate. Overall, diet EG significantly increased the molar proportion of butyrate with respect to diets $E$ and EB and over time the proportion decreased, there being significantly greater amounts after 4 weeks than at either 8 or 12 weeks. But it is evident from the interaction that the trends with time were not the same for each diet. With the exception of diets $\mathrm{E}$ and EG given for 4 weeks, the molar proportion of faecal butyrate was substantially less than in caecal material.

\section{DISCUSSION}

In the present paper an experiment is described in which the rat is used to examine the metabolism of wheat bran and gum arabic in the rat colon. This type of study in the rat is increasingly being used to complement experiments in man (Nyman \& Asp, 1982; Nyman et al. 1986; Walter et al. 1986; Wise et al. 1986). Measurements of bacterial mass, fibre metabolism and fibre residue have been made in these experiments, each experiment giving different insights into fibre metabolism in the colon. Since it is known that some non-fibre components of the diet, e.g. starch (Stephen et al. 1983), pass to the caecum, it was of interest to study caecal fibre metabolism with a diet which is efficiently absorbed, thus minimizing dietary components passing with fibre to the caecum (Russell, 1985). Flexical is an elemental diet which contains amino acids and simple sugars that require no digestion and will have no influence on stool weight. This elemental diet should be absorbed totally from the foregut, leaving the fibre alone to pass to the caecum (Russell, 1985). The chosen indices of fibre metabolism were dry stool weight, bacterial mass, $\mathrm{H}_{2}, \mathrm{CH}_{4}$ and SCFA. Stool weight has often been shown to be influenced by diet (Williams \& Olmsted, 
$1936 \mathrm{~b}$ ). Cereal fibres are known to be substantial stool-bulking agents (Eastwood et al. 1973), whilst fruit and vegetables have been shown to have modest effects (Cummings et al. 1978). Gums and pectins have been shown to have no significant influence on stool weight (Kay \& Truswell, 1977).

Bacterial mass is important, since fibre may be fermented in the colon with subsequent bacterial proliferation. Gum arabic is a fermentable fibre source whereas bran is relatively inert. During such fermentation it is likely that bacterial mass may increase and that such indices of metabolism as SCFA, $\mathrm{CH}_{4}$ and $\mathrm{H}_{2}$ would increase.

The absolute values for dry stool weight with the diet $\mathrm{E}$ were small $(0.7 \mathrm{~g} / \mathrm{d})$ compared with those results previously obtained for rats fed on standard rat diets $(3.2 \mathrm{~g} / \mathrm{d}$ ) (Walter et al. 1986). Only dry stool weight was recorded because of the variable effect of drying of the faecal pellets in an animal-house environment (approximately $20^{\circ}$ ). The addition of bran to diet $\mathrm{E}$ did increase dry stool weight $(1.0 \mathrm{~g} / \mathrm{d})$ but not to values found previously with an unsupplemented fibre-free complex diet (1.98 g/d) (Walter et al. 1986). Gum-arabic supplementation had no significant effect on dry stool weight. In animals fed on the elemental diets, the colon would receive the fibre supplements free of nutrients, since these would have been absorbed proximally. When wheat bran or gum arabic was added to an elemental diet an 8-week period of feeding was necessary before dry stool weight stabilized, and such a period of feeding would be necessary before meaningful measurements could be made using this dietary regimen. Elsenhans et al. (1981) reported that a period of 7-8 weeks would appear to be reasonable to study adaptive responses of long-term feeding of carbohydrate-gelling agents added to a fibre-free diet.

Dry caecal contents and caecal sac weight were greatest with diet EG. This increase, established at 4 weeks, was paralleled by an increased caecal DAPA content. DAPA is only an indirect indicator of bacterial mass, although very useful (Czerkawski, 1974), and is found in nearly all bacterial cell walls but in varying concentrations depending on the species (Work \& Dewey, 1953). An increase in DAPA almost certainly means an increase in total bacterial mass but could, on the other hand, result from the proliferation of a bacterial species with a high DAPA content. Whilst diet EG resulted in an increased faecal DAPA, this was not sufficient to increase stool weight. It is possible that diet EG is associated with prolonged residence time in the caecum. The larger bacterial mass with diet EG resulted in an increased SCFA production, but was not associated with an increase in $\mathrm{H}_{2}$ and $\mathrm{CH}_{4}$ production. Indeed both $\mathrm{H}_{2}$ and $\mathrm{CH}_{4}$ were abolished with diet EG after 12 weeks. This was different from that in man, where after 3 weeks $\mathrm{H}_{2}$ production increased with gum-arabic ingestion (McLean Ross et al. 1983) although this response may be dose related.

The major SCFA produced in the caecum was acetate, being three times propionate production and six times butyrate production. The differences between the two fibres were modest for butyrate at 8 weeks with diet EB. The increased faecal SCFA on diet EB may have been due to entrapped SCFA in the bran matrix, but with EG the reason is less obvious.

On the elemental diet caecal weight, bacterial mass and the production of SCFA increased with the addition of gum arabic. These changes were not found when wheat bran was added to the diet. It is of interest that the production of $\mathrm{H}_{2}$ and $\mathrm{CH}_{4}$ disappeared both with diets EG and EB. This suggests that the production of $\mathrm{H}_{2}$ and $\mathrm{CH}_{4}$ is independent of the metabolic processes which result in an increased bacterial mass and fermentation of gum arabic. These findings contrast with experiments in man (McLean Ross et al. 1983) where the breath $\mathrm{H}_{2}$ increased with gum-arabic ingestion. It is possible that an elemental diet is deficient in the substrate for $\mathrm{H}_{2}$ and $\mathrm{CH}_{4}$ production. This missing substrate is unlikely 
to be starch as there is possibly some starch provided by the wheat bran. It is also possible that the bacterial species which ferments dietary constituents or secreted mucpolysaccharides to $\mathrm{H}_{2}$ and $\mathrm{CH}_{4}$ do not grow on this restricted diet.

It is clear from the variation in results in these experiments that stability in caecal metabolism did not develop during the period of study ( 3 months). It is possible that there is a periodicity in the production of SCFA, etc. which was not shown in detail for the timeintervals that were chosen. Nyman \& Asp (1982) studied rats for $5 \mathrm{~d}$ after a $4 \mathrm{~d}$ adaptation period. Their results for the metabolism of a wide range of dietary fibres were similar to results obtained when those fibres were studied in man over a 3-week period (Nyman et al. 1986).

The present experiments have demonstrated that when wheat bran is given with an elemental diet there is no increased bacterial mass or metabolic activity in the caecum. However, the stool weight increases. When gum arabic is added to an elemental diet there is increased bacterial mass and production of SCFA, but no effect on stool weight. There is also an unexplained disappearance of $\mathrm{H}_{2}$ and $\mathrm{CH}_{4}$ production, suggesting a selective effect of the elemental diet on bacterial metabolism.

The authors are grateful for financial support from Richardson-Vicks Europe Ltd, Egham, Surrey.

\section{REFERENCES}

Cummings, J. H., Southgate, D. A. T., Branch, W., Houston, H., Jenkins, D. J. A. \& James, W. (1978). Lancet i, 5-9.

Czerkawski, J. W. (1974). Journal of the Science of Food and Agriculture 25, 45-55.

Eastwood, M. A., Kirkpatrick, R., Mitchell, W. D., Bone, A. \& Hamilton, T. (1973). British Medical Journal iv, 392-394.

Eastwood, M. A. \& Mitchell, W. D. (1976). In Fibre in Human Nutrition, pp. 109-129 [G. A. Spiller and R. J. Amen, editors]. New York: Plenum Press.

Elsenhans, B., Blume, R. \& Caspary, W. F. (1981). American Journal of Nutrition 34, 1837-1848.

Kay, R. M. \& Truswell, A. S. (1977). American Journal of Clinical Nutrition 30, 171-175.

Leegwater, D. C., de Groot, A. P. \& Van Kalmthout-Kuyper, M. (1974). Food and Cosmetics Toxicology 12 , 687-697.

McKay, L. F. (1981). A study of breath methane excretion. PhD Thesis, University of Edinburgh.

Mclean Ross, A. H., Brydon, W. G., Eastwood, M. A., Anderson, J. R. \& Anderson, D. M. W. (1983). American Journal of Clinical Nutrition 37, 368-375.

Nyman, M. \& Asp, N. G. (1982). British Journal of Nutrition 47, 357-366.

Nyman, M., Asp, N. G., Cummings, J. \& Wiggins, H. (1986). British Journal of Nutrition 55, 487-496.

Rodkey, F. L., Collinson, H. A. \& O'Neal, J. D. (1972). Journal of Applied Physiology 33, 256-260.

Russell, R. I. (1985). Proceedings of the Nutrition Society 44, 87-93.

Spiller, G. A., Chernoff, M. C., Hill, R. A., Gates, J. E., Nassar, J. H. \& Shipley, E. A. (1980). American Journal of Clinical Nutrition 33, 754-759.

Stephen, A. M., Haddad, A. C. \& Phillips, S. F. (1983). Gastroenterology 85, 589-596.

Tadesse, K., Smith, A., Brydon, W. G. \& Eastwood, M. A. (1979). Journal of Chromatography 171, 416-418.

Walter, D. J. (1985). Fibre metabolism in the rat. PhD Thesis, University of Edinburgh.

Walter, D. J., Eastwood, M. A., Brydon, W. G. \& Elton, R. A. (1986). British Journal of Nutrition 55, 465-479.

Williams, R. D. \& Olmsted, W. G. (1936a). Journal of Nutrition 11, 433-449.

Williams, R. D. \& Olmsted, W. G. (1936 b). Annals of Internal Medicine 10, 717-727.

Winitz, M., Adams, R. F., Seedman, D. A., Davis, P. N., Jayko, L. G. \& Hamilton, J. A. (1970). American Journal of Clinical Nutrition 23, 546-559.

Wise, A., Mallett, A. K. \& Rowland, I. R. (1986). Toxicology 38, 241-248.

Work, E. \& Dewey, D. L. (1953). Journal of General Microbiology 9, 394409. 